\title{
Staphylococcus spp. from wild mammals in Aragón (Spain): antibiotic resistance status
}

\author{
Leticia Alcalá García ${ }^{1}$, Carmen Torres ${ }^{2}$, Antonio Rezusta López ${ }^{3}$, \\ Carmelo Ortega Rodríguez ${ }^{1}$, Jesús Orós Espinosa ${ }^{1}$, Carmen Simón Valencia ${ }^{1 凶}$ \\ ${ }^{1}$ Department of Animal Pathology, Infectious Diseases and Epidemiology, \\ Veterinary Faculty of Zaragoza, 50013, Zaragoza, Spain \\ ${ }^{2}$ Department of Food and Agriculture, Area of Biochemistry and Molecular Biology, \\ University of La Rioja, 26006, Logroño, Spain \\ ${ }^{3}$ Microbiology Service, Hospital Miguel Servet, IIS Aragón, \\ Universidad de Zaragoza, 50009, Zaragoza, Spain \\ mcsimon@unizar.es
}

Received: March 1, $2020 \quad$ Accepted: August 24, 2020

\begin{abstract}
Introduction: Antimicrobial resistance is a global health threat. It has been studied in humans and domestic animals, but there is a lack of data on wild animals. The objective of this study is the elucidation of its patterns in Staphylococcus spp. isolated from wild mammals of the Autonomous Community of Aragón (Spain). Material and Methods: A total of 103 mammals (Artiodactyla, Carnivora, Chiroptera, Erinaceomorpha, and Lagomorpha) were studied. A recovery centre provided 32 and hunting 71. Nasal and faecal samples yielded 111 staphylococci, which were identified by matrix-assisted laser desorption/ionization-time of flight mass spectrometry. A susceptibility test to 11 antibiotics was carried out, and statistical analysis was performed. Results: Some differences were detected in bacterial prevalence depending on how the mammal fed. Artiodactyla, mainly hunted, were predisposed to carry coagulase-positive staphylococci. The staphylococci species recovered were resistant to at least two classes of antibiotics, and were disseminated in all of the geographical areas studied. Conclusion: Resistant staphylococci are widely distributed in the wild mammals in the areas of the study, but the resistance quantified in them is lower than that to be expected if the use of antibiotics in farms had a direct influence on the wildlife and its environment. On the other hand, resistance to antibiotics restricted to human use was widely disseminated in various wild animal species.
\end{abstract}

Keywords: wild mammals, Staphylococcus spp., antibiotic resistance, epidemiology.

\section{Introduction}

In a global world, it is wholly understood that animals, humans, and environment are interconnected. The World Health Organisation (WHO), World Organisation for Animal Health (OIE), and Food and Agriculture Organisation (FAO), have joined efforts (8) to propose measures together against health risks at the animal-human-ecosystems interface. The OIE developed the "Strategy on Antimicrobial Resistance and Prudent Use of Antimicrobials" in 2016, to survey the emergence of antibiotic-resistant (AR) organisms (28). The WHO published a list of the main resistant bacteria including methicillin-resistant Staphylococcus aureus (MRSA), and a warning of its decreasing susceptibility to vancomycin in 2014 (29). A little later, coagulase- negative Staphylococcus (CoNS) began to be considered as a source of resistance genes for humans and animals (23). Generally speaking, misuse of antibiotics in treatment of humans and animals is considered the main factor favouring the spread of resistant genes and bacteria that will also reach the food chain and humans $(10,27)$. Imprudent antimicrobial application examples included wrong dosage regimens, self-medication, and their incorrect use in intensive animal production. Skin and faeces of domestic animals contribute to the staphylococci spreading into the environment (10). Wastewater is one important source of resistant genes and bacteria and, considering the continuous movement of people, animal and products around the world, it represents a significant path for the spread of genes and 
bacteria far away from the point where resistance was originated $(11,16)$.

The aim of this study was to detect the resistant phenotype profile of Staphylococci, with special attention to methicillin-resistant coagulase-positive Staphylococcus (CoPS) isolated from wild mammals from the Autonomous Community of Aragón (Spain), and to look for factors affecting the pattern of bacterial resistance.

\section{Material and Methods}

Study samples. Nasal and rectal samples from each of 103 wild mammals, making 206 samples in total, (Table 1) were collected in the Autonomous Community of Aragón (Spain) between 2012 and 2015. Samples from 32 animals were provided by the Centre of Wild Fauna Recovery of La Alfranca (CWFR-LA), Zaragoza (Aragón, Spain), and material from 71 mammals was put at our disposal by veterinarians attending hunts. Samples were collected by means of sterile swabs in Amies medium, in the first hours after the animal's arrival at the CWFR-LA or immediately after its being killed as hunting prey. Epidemiological data collected from the animals were species, order, animal age (neonates and sub-yearlings $<$ one year, young $>$ one year $<$ two years, and adult $>$ two years), sex, basic type of diet (carnivorous, herbivorous, omnivorous, piscivorous, invertebrate eater), and habituation to scavenging (carrion eaters). The mammals came from five different geographical areas (classified by altitude).

Isolation and identification of staphylococci. Samples were seeded in mannitol salt agar, (CM0085, Oxoid S.A., Spain), with and without oxacillin. Gram stain, catalase, oxidase, and coagulase tests were performed. Selected colonies were sub-cultured in Columbia blood agar base (blood agar base sheep blood, PB0115, Oxoid S.A., Spain), in order to be identified by matrix-assisted laser desorption/ionisation-time of flight mass spectrometry (MALDI-TOF MS) through the proteomic fingerprint on a Biotyper 3 system (Bruker, USA), following the manufacturer's instructions.

Antibiotic susceptibility test. Antibiotic resistance was tested by the Kirby-Bauer method, following the instructions of the Clinical \& Laboratory Standards Institute (USA) (4). Penicillin (PEN, $10 \mathrm{U})$, cefoxitin (FOX, $30 \mu \mathrm{g}$ ), teicoplanin (TEI, $30 \mu \mathrm{g}$ ), tetracycline (TE, $30 \mu \mathrm{g}$ ), erythromycin (ERY, $15 \mu \mathrm{g}$ ), clindamycin (CLI, $2 \mu \mathrm{g})$, chloramphenicol (CL, $30 \mu \mathrm{g})$, gentamicin (GEN, $10 \mu \mathrm{g}$ ), tobramycin (TOB, $10 \mu \mathrm{g}$ ), streptomycin (STR, $10 \mu \mathrm{g}$ ), lincomycin (LIN, $15 \mu \mathrm{g}$ ), ciprofloxacin (CIP, $5 \mu \mathrm{g}$ ), sulfamethoxazole-trimethoprim (SXT, $1.25-23.75 \mu \mathrm{g}$ ), fusidic acid (FA, $10 \mu \mathrm{g}$ ), and mupirocin (MUP, $5 \mu \mathrm{g}$ ) were studied. A multidrug-resistant (MDR) isolate is defined as one with acquired non-susceptibility to at least one agent in three or more antimicrobial categories (15). A total of $23 \mathrm{~S}$. aureus isolates were characterised in a previous paper (22), in which the phenotype/genotype of antimicrobial resistance, virulence gene content, and molecular typing of the isolates were reported.

Statistical analysis. The frequency distribution of the main factors along with the detection of association between the epidemiological data was recorded, Staphylococcus was isolated and the detected antibiotic resistance was calculated. That was performed with Epi Info 7.1.5.2 software (https://www.cdc.gov/epiinfo). Chi squared $\left(\chi^{2}\right)$ was calculated for qualitative variables to detect the existence of association ( $\mathrm{P} \leq 0.05)$. Occasionally the Fisher exact test was applied.

\section{Results}

There were 111 isolates recovered in which there were identified 15 different Staphylococcus species from 15 mammal species (Tables 1 and 2), most of them retrieved from nasal swabs. A $73.7 \%$ proportion of samples of Carnivora (Table 1) rescued in the CWFRLA carried staphylococci (Table 1). The order Lagomorpha gave a lower proportion of staphylococci isolation by samples $(35.0 \%)$ than other orders. More than $60 \%$ of carnivorous $(16 / 22)$, invertebrate-eater $(17 / 24)$, omnivorous (29/44), and piscivorous (5/8) animals had isolates recovered from them, while $40.9 \%$ of herbivorous animals had $(45 / 110)(\mathrm{P} \leq 0.05)$. A total of $26 \mathrm{CoPS}$ and $85 \mathrm{CoNS}$ were isolated. The higher percentage of CoPS was obtained from hunted mammals $(84.6 \% ; 22 / 26)$ and the order Artiodactyla (73.1\%; 19/26). CoNS were found equally in both hunted $(\mathrm{n}=43)$ and rescued mammals $(\mathrm{n}=42)$. The most prevalent staphylococci were S. sciuri $(30.6 \%)$ and S. aureus (20.7\%) (Table 2). S. sciuri was isolated from 11 different species while $S$. aureus was isolated from hedgehog, mouflon, red deer, wild rabbit, and wild boar, in which the $50 \%$ of isolates were this species $(11 / 22)$ (Table 2). S. aureus predominated in 11 Artiodactyla $(50.0 \% ; 19 / 38)$ (Table 2$)$, but none was isolated from Carnivora. Wild rabbits carried a low percentage of S. aureus $(7.9 \% ; 3 / 38)$.

Antibiotic phenotypical resistance to FA was high (64\%), and in declining order resistance to other antibiotics was to PEN (42.3\%), LIN (32.4\%), FOX (20.7\%), MUP (19.8\%), and ERY (13.5\%). The remaining studied antibiotics showed lower than $10 \%$ of isolates to be resistant, and the lower limit was SXT - 0\% (Table 3). A low prevalence of MDR staphylococci isolates was detected in the studied population $(7.2 \% ; 8 / 111)$. The majority of FA-resistant isolates were CoNS (72.9\%) (Table 4) obtained from rescued mammals $(76.1 \%)$, where $S$. sciuri was predominant $(\mathrm{P} \leq 0.05)$. The five isolates from the common otter were resistant to FA (Table 3). Staphylococci resistant to MUP were mainly isolated from hunted mammals $(27.7 \% ; 18 / 65)$ and 
Table 1. Species of wild mammals included in the study

\begin{tabular}{|c|c|c|c|c|c|c|c|}
\hline Order & Species & Scientific name & Origin & Scavenger & $\mathrm{N}$ & Isolates & $\begin{array}{l}\text { \% by } \\
\text { sample* }\end{array}$ \\
\hline \multirow[t]{5}{*}{ Artiodactyla $(\mathrm{n}=32)$} & Iberian ibex & Capra pyrenaica & CWFR-LA $^{\mathrm{a}}$ & & 1 & 1 & 50.0 \\
\hline & Mouflon & Ovis orientalis & Hunting & & 4 & 6 & 75.0 \\
\hline & Red deer & Cervus elaphus & Hunting & & 9 & 6 & 33.3 \\
\hline & Roe deer & Capreolus & Hunting & & 1 & 3 & 150 \\
\hline & Wild boar & Sus scrofa & Hunting & & 17 & 22 & 64.7 \\
\hline Total & & & & & 32 & 38 & 59.4 \\
\hline \multirow[t]{7}{*}{ Carnivora $(n=19)$} & American mink & Neovison vison & CWFR-LA & $\mathrm{X}$ & 6 & 8 & 66.6 \\
\hline & Badger & Meles meles & CWFR-LA & $\mathrm{X}$ & 3 & 5 & 83.3 \\
\hline & Beech marten & Martes foina & CWFR-LA & $X$ & 2 & 2 & 50.0 \\
\hline & Common genet & Genetta genetta & CWFR-LA & $\mathrm{X}$ & 1 & 1 & 50.0 \\
\hline & Common otter & Lutra lutra & CWFR-LA & $\mathrm{X}$ & 3 & 5 & 83.3 \\
\hline & Red fox & Vulpes vulpes & CWFR-LA & $\mathrm{X}$ & 3 & 8 & 133.0 \\
\hline & Weasel & Mustela nivalis & CWFR-LA & $\mathrm{X}$ & 1 & 0 & 0 \\
\hline Total & & & & & 19 & 28 & 73.7 \\
\hline Chiroptera $(\mathrm{n}=1)$ & $\begin{array}{l}\text { European free-tailed } \\
\text { bat }\end{array}$ & Tadarida teniotis & CWFR-LA & & 1 & 1 & 50.0 \\
\hline Erinaceomorpha $(\mathrm{n}=11)$ & Hedgehog & Erinaceus europaeus & CWFR-LA & & 11 & 15 & 68.2 \\
\hline \multirow[t]{2}{*}{ Lagomorpha $(\mathrm{n}=40)$} & Wild rabbit & $\begin{array}{l}\text { Oryctolagus } \\
\text { cuniculus }\end{array}$ & Hunting & & 38 & 27 & 35.5 \\
\hline & Granada hare & Lepus granatensis & Hunting & & 2 & 1 & 100.0 \\
\hline Total & & & & & 40 & 28 & 35.0 \\
\hline & 16 species & & $\begin{array}{l}\text { Total } \\
\text { mammals }\end{array}$ & & 103 & 111 & 53.9 \\
\hline
\end{tabular}

a - Centre of Wild Fauna Recovery of La Alfranca (Spain); * - two samples per animal

Table 2. Staphylococcus spp. obtained in this study from the total samples of the wild mammals studied

\begin{tabular}{|c|c|c|c|c|c|c|c|c|c|c|c|c|c|c|c|c|c|}
\hline Staph. spp. ${ }^{\mathrm{q}}$ & $\mathrm{A}^{\mathrm{a}}$ & $\mathrm{B}^{\mathrm{b}}$ & $\mathrm{Bm}^{\mathrm{c}}$ & $\mathrm{Cg}^{\mathrm{d}}$ & $\mathrm{Co}^{\mathrm{e}}$ & $\mathrm{G}^{\mathrm{f}}$ & $\mathrm{H}^{\mathrm{g}}$ & $\mathrm{I}^{\mathrm{h}}$ & $M^{\mathrm{i}}$ & $\mathrm{Ft}^{\mathrm{j}}$ & $\mathrm{R}^{\mathrm{k}}$ & $\mathrm{Rd}^{\mathrm{l}}$ & $\mathrm{Rf}^{\mathrm{m}}$ & $\mathrm{W}^{\mathrm{n}}$ & $\mathrm{Wb}^{\circ}$ & $\mathrm{Wi}^{\mathrm{p}}$ & $\begin{array}{l}\text { Total } n \\
(\%)\end{array}$ \\
\hline S. aureus & & & & & & & 1 & & 4 & & & 4 & & & 11 & 3 & $23(20.7)$ \\
\hline S. chromogenes & & & & & & 1 & & & & & & & & & 5 & 1 & $7(6.3)$ \\
\hline S. delphini & 2 & & & & & & & & & & & & & & & & $2(1.8)$ \\
\hline S. epidermidis & & & & & & & & & & & & & & & 1 & & $1(0.9)$ \\
\hline S. equorum & & & 1 & & & & 1 & & 1 & & 2 & & & & 1 & 11 & $17(15.3)$ \\
\hline S.felis & & 1 & & & & & & & & & & & & & & & $1(0.9)$ \\
\hline S. fleurettii & & & & & 2 & & & & & & & & & & & & $2(1.8)$ \\
\hline S. hyicus & & & & & & & & & & & & & & & 1 & & $1(0.9)$ \\
\hline S. nepalensis & & & & & & & 1 & & & & & & & & & & $1(0.9)$ \\
\hline S. pseudintermedius & & & & & & & & & & & & & 1 & & & & $1(0.9)$ \\
\hline S. saprophyticus & & & & & & & & & & & & 1 & & & & & $1(0.9)$ \\
\hline S. sciuri & 3 & 4 & & 1 & 3 & & 8 & & 1 & 1 & 1 & & 6 & & 2 & 4 & $34(30.6)$ \\
\hline S. simulans & & & & & & & 2 & & & & & & & & & & $2(1.8)$ \\
\hline S. vitulinus & 3 & & & & & & 2 & & & & & 1 & & & 1 & & $7(6.3)$ \\
\hline S. xylosus & & & 1 & & & & & 1 & & & & & 1 & & & 8 & $11(9.9)$ \\
\hline $\begin{array}{l}\text { Total staphylococci by } \\
\text { mammal (n) }\end{array}$ & 8 & 5 & 2 & 1 & 5 & 1 & 15 & 1 & 6 & 1 & 3 & 6 & 8 & 0 & 22 & 27 & 111 \\
\hline
\end{tabular}

${ }^{\mathrm{a}}$ American mink; ${ }^{\mathrm{b}}$ Badger; ${ }^{\mathrm{c}}$ Beech marten; ${ }^{\mathrm{d}}$ Common genet; ${ }^{\mathrm{e}}$ Common otter; ${ }^{\mathrm{f}}$ Granada hare; ${ }^{\mathrm{g}}$ Hedgehog; ${ }^{\mathrm{h}}$ Iberian ibex; ${ }^{\mathrm{i}}$ Mouflon; ${ }^{\mathrm{j}}$ European free-tailed bat; ${ }^{\mathrm{k}}$ Roe deer; ${ }^{1}$ Red deer; ${ }^{\mathrm{m}}$ Red fox; ${ }^{\mathrm{n}}$ Weasel; ${ }^{\circ}$ Wild boar; ${ }^{\mathrm{p}}$ Wild rabbit; ${ }^{\mathrm{q}}$ Staphylococcus spp. 
Table 3. Frequency of Staphylococcus spp. isolates resistant to the studied antibiotics by animal species

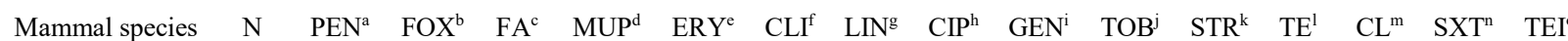

\begin{tabular}{|c|c|c|c|c|c|c|c|c|c|c|c|c|c|c|c|c|}
\hline American mink & 8 & 4 & 1 & 6 & & & 1 & 3 & & & & & & & & \\
\hline Badger & 5 & 4 & 1 & 5 & 2 & & & 1 & & & & & & & & \\
\hline Beech marten & 2 & 1 & 1 & & & & & & & & & & 1 & & & \\
\hline Granada hare & 1 & 1 & 1 & 1 & 1 & & & & & & & & & & & \\
\hline Common genet & 1 & 1 & & 1 & & & & & & & & & & & & \\
\hline Common otter & 5 & 5 & 3 & 5 & & & & 4 & & & & & & & & \\
\hline Hedgehog & 15 & 7 & 3 & 11 & & 1 & 1 & 6 & & & & 1 & 1 & & & \\
\hline Mouflon & 6 & 1 & 2 & 1 & & 3 & & 1 & & & & 1 & & & & \\
\hline Free-tailed bat & 1 & & & & & 1 & & & & & & 1 & & & & \\
\hline Red deer & 8 & 1 & & 2 & 1 & 3 & & 2 & & & & 1 & 3 & 1 & & \\
\hline Red fox & 7 & 3 & 3 & 5 & 1 & & 2 & 4 & & & & & & & & \\
\hline Roe deer & 2 & 2 & & 2 & 1 & & & 1 & & & & & 1 & & & \\
\hline Iberian ibex & 1 & 1 & & 1 & & & & & & 1 & & & 1 & & & \\
\hline Weasel & 0 & & & & & & & & & & & & & & & \\
\hline Wild boar & 22 & 2 & 1 & 11 & 7 & 3 & 1 & 4 & & & & 4 & 3 & 1 & & \\
\hline Wild rabbit & 27 & 14 & 7 & 20 & 9 & 4 & 2 & 10 & 3 & 1 & 1 & 2 & 3 & & & 1 \\
\hline Total & 111 & 47 & 23 & 71 & 22 & 15 & 7 & 36 & 3 & 2 & 1 & 10 & 13 & 2 & 0 & 1 \\
\hline$\%$ & 100 & 42.3 & 20.7 & 64 & 19.8 & 13.5 & 6.3 & 32.4 & 2.7 & 1.8 & 0.9 & 9.0 & 11.7 & 1.8 & 0 & 0.9 \\
\hline
\end{tabular}

${ }^{\mathrm{a}}$ penicillin; ${ }^{\mathrm{b}}$ cefoxitin; ${ }^{\mathrm{c}}$ fusidic acid; ${ }^{\mathrm{d}}$ mupirocin; ${ }^{\mathrm{e}}$ erythromycin; ${ }^{\mathrm{f}}$ clindamycin; ${ }^{\mathrm{g}}$ lincomycin; ${ }^{\mathrm{h}}$ ciprofloxacin; ${ }^{\mathrm{i}}$ gentamycin; ${ }^{\mathrm{j}}$ tobramycin; ${ }^{\mathrm{k}}$ streptomycin; ${ }^{1}$ tetracycline; ${ }^{\mathrm{m}}$ chloramphenicol; ${ }^{\mathrm{n}}$ sulfamethoxazole-trimethoprim; ${ }^{\circ}$ teicoplanin

Table 4. Results of the statistical analysis of Staphylococcus spp. resistance to ERY, FA, and PEN related to the coagulase classification, the wild mammals' origins, and their orders

\begin{tabular}{|c|c|c|c|c|c|c|c|}
\hline Antibiotics & Coagulase $(\mathrm{N})$ & $\begin{array}{l}\text { Resistant } \\
\text { isolates, } \mathrm{n}(\%)\end{array}$ & Coagulase $(\mathrm{N})$ & $\begin{array}{l}\text { Resistant } \\
\text { isolates, } \mathrm{n}(\%)\end{array}$ & Odds Ratio & $\begin{array}{l}\text { Lower } \\
\text { limit }\end{array}$ & Upper limit \\
\hline $\begin{array}{l}\text { Fusidic } \\
\text { acid }\end{array}$ & $\mathrm{CoN}^{\mathrm{a}}(85)$ & $62(72.9)^{*}$ & $\mathrm{CoP}^{\mathrm{b}}(26)$ & $9(34.6)$ & 5.0918 & 1.9909 & 13.0225 \\
\hline Penicillin & $\mathrm{CoN}^{\mathrm{a}}(85)$ & $43(50.6)^{*}$ & $\mathrm{CoP}^{\mathrm{b}}(26)$ & $5(19.2)$ & 4.3000 & 14.838 & 12.4609 \\
\hline \multirow[t]{2}{*}{$\begin{array}{l}\text { Erythromyc } \\
\text { in }\end{array}$} & $\mathrm{CoN}^{\mathrm{a}}(85)$ & $8(9.4) *$ & $\mathrm{CoP}^{\mathrm{b}}(26)$ & $7(26.9)$ & 3.5461 & 1.11434 & 11.0011 \\
\hline & Origin $(\mathrm{N})$ & & Origin $(\mathrm{N})$ & & & & \\
\hline $\begin{array}{l}\text { Fusidic } \\
\text { acid }\end{array}$ & CWFR-LA ${ }^{\mathrm{c}}(46)$ & $35(76.1)^{*}$ & Hunting (65) & $36(55.4)$ & 2.5631 & 5.9109 & 14.2860 \\
\hline \multirow[t]{2}{*}{ Penicillin } & CWFR-LA ${ }^{\mathrm{c}}(46)$ & $27(58.7)^{*}$ & Hunting (65) & $20(30.8)$ & 1.1114 & 3.1974 & 7.0353 \\
\hline & Order $(\mathrm{N})$ & & Order $(\mathrm{N})$ & & & & \\
\hline \multirow[t]{2}{*}{$\begin{array}{l}\text { Fusidic } \\
\text { acid }\end{array}$} & Artiodactyla vs (39) & $17(43.59)$ & Carnivora* (28) & $22(78.57)$ & 4.7461 & 11.249 & 1.0868 \\
\hline & & & Lagomorpha* (28) & $21(75.0)$ & 1.5755 & 8.2305 & 14.7275 \\
\hline \multirow[t]{3}{*}{ Penicillin } & Artiodactyla vs (39) & $7(15.4)$ & Carnivora* (28) & $18(64.3)$ & 14.2860 & 2.6702 & 5.27426 \\
\hline & & & Erinaceomorpha* (15) & $7(46.7)$ & 3.8820 & 25.3810 & 1.7476 \\
\hline & & & Lagomorpha* (28) & $15(53.6)$ & 1.3396 & 4.0000 & 15.9236 \\
\hline
\end{tabular}

* $\mathrm{P} \leq 0.05 ;{ }^{\mathrm{a}}$ coagulase-negative; ${ }^{\mathrm{b}}$ coagulase-positive; ${ }^{\mathrm{c}}$ Centre of Wild Fauna Recovery of La Alfranca (Spain)

predominated in the omnivorous $(33.3 \% ; 9 / 29)$ and herbivorous $(26.7 \% ; 12 / 45)$ groups compared to the carnivorous one $(5.6 \% ; 1 / 16)(\mathrm{P} \leq 0.05)$.

The probability of isolating PEN-resistant staphylococci was 4.3-fold higher for CoNS than for
CoPS (Table 4). This probability was $8.2,5.3$ and 4.0-fold higher for Carnivora $(64.3 \%$; 18/28), Lagomorpha $(53.6 \% ; 15 / 28)$ and Erinaceomorpha $(46.7 \% ; 7 / 15)$, respectively, than for Artiodactyla $(15.4 \% ; 7 / 39)$. It was also 3.4 higher in scavenger 
mammals $(64.3 \% ; 22 / 28)$ than in non-scavenger animals $(35 \% ; 49 / 83)$. The prevalence of FOX-resistant isolates followed the same pattern as that observed for $\beta$-lactam antibiotics, without significant differences for CoPS and CoNS. Three S. aureus and 19 CoNS (19.8\% of the total isolates) were resistant to PEN and FOX simultaneously, being phenotypically methicillin resistant (MRS). Isolates resistant to ERY were 3.5-fold more common as CoPS (Table 4). Hunted wild mammals carried a higher percentage of staphylococci with this resistance $(20 \%$; $13 / 65)$ than rescued mammals $(4.4 \% ; 2 / 46)$. The prevalence of resistance to ERY and LIN (Table 3) was higher for LIN (32.4\%) and was highest in wild rabbits $(37 \% ; 10 / 27)$. The Carnivora order carried a higher proportion of staphylococci resistant to LIN (42.9\%; $12 / 28)$ than Artiodactyla $(20.5 \% ; 8 / 39)(\mathrm{P} \leq 0,05)$. Resistance to this antibiotic was also associated with the type of diet the mammals ate, piscivores evidencing the highest proportion (4/5), and omnivores the lowest $(18.5 \%$; 5/27). Few associations were observed for isolates resistant to TE due to the wide distribution of resistance between variables.

\section{Discussion}

Although nasal samples are usually taken to isolate staphylococci from wild animals, since nasal secretions easily disseminate them by contact or proximity $(14,20$, 21 ), we also isolated staphylococci from faeces, since we consider it an important route of dissemination of resistant bacteria into the environment. Staphylococci were mainly isolated from Carnivora (mostly scavengers) and Erinaceomorpha rescued by the CWFRLA. Conversely, the order Lagomorpha gave the lower proportion of isolates, which was probably related to feeding habits, considering the percentages of detected in carnivores, invertebrate eaters, omnivores, and piscivores.

CoPS were mainly isolated from hunting mammals and the order Artiodactyla, including herbivorous and also omnivorous mammals which frequently visit human habitats where they could come into contact with human origin bacteria. It is of note that $S$. aureus has been isolated from wild fauna in Europe (18). In our study, $50 \%$ of wild boar isolates were $S$. aureus, this number being higher than that reported by Porrero et al. (21), but similar to that found by Seinige et al. (24) in wild boars from Lower Saxony (Germany) (45.5\%; $\mathrm{n}=111$ ). Additionally, mouflon and red deer yielded an even higher proportion of $S$. aureus isolates (4/6); these mammals are herbivorous, pointing to environmental pollution as the main source of this bacteria. This is in line with the non-achievement of $S$. aureus isolation from Carnivora (including carrion eaters), regarded as more independent individuals (5), a characteristic which hinders direct transmission (14, 21). Interestingly, although wild rabbits were the most represented mammals in this study, they carried a low percentage of $S$. aureus $(8 \% ; 3 / 38)$, it being clearly lower than that observed in domestic rabbits in Spain (29\% of healthy rabbits) (25). The free-living characteristic of wild rabbits, together with less contact between individuals (5) could be a protective factor. The most prevalent staphylococci were CoNS, in which S. sciuri was predominant. This microorganism has usually had animal origin and for that reason, it has also been associated with antibiotic resistance in farm animals (23).

Regarding antibiotic resistance, it should be mentioned that the five isolates from common otters (piscivores) were resistant to FA. It is important to highlight that the Ebro river was the habitat for four of these animals, because this circumstance reinforces the well-known importance of rivers for dissemination of antibiotics, mobile genetic elements of resistance and resistant bacteria $(11,16,26)$. Since fusidic acid is only commercialised as a cream for staphylococcal infections, human sources could be associated with this FA resistance (3). Hunted mammals were the main source of staphylococci resistant to MUP and these predominated in omnivores and herbivores compared to carnivores. Therefore, resistance to this antibiotic appears to be related to the environment and plants, as other authors observed $(11,16,26)$. Mupirocin is another topical antibiotic for prevention of human staphylococcal skin infections and eradication of MRSA. Consequently, resistance to MUP in wild animal isolates could also be related to human sources.

Beta-lactam antibiotics are the first-choice treatment for staphylococcal infections and a high proportion of isolates resistant to them (mainly CoNS) are frequently found in many human and animal environments (12), which can explain the high prevalence of resistance (42\%) found in this study. Staphylococci which are non-susceptible to PEN were found to a greater extent in the Carnivora, Lagomorpha, and Erinaceomorpha orders than in Artiodactyla or animals with scavenger habits. Since penicillin was one of the most commonly sold antibiotics in Europe in 2013, 2014, and 2015 in both human and veterinary medicine (7), the source of this resistance could be linked to penicillin's wide use on dairy, pig, and poultry farms, to its moderate bio-accumulation potential in plants (26), and to the exposure to dead animals from farms, this last source being especially relevant to carrion eaters (6). It is of note that we detected $19.8 \%$ of staphylococci resistant to PEN and FOX simultaneously to be methicillin resistant (MRS). MRSA has been widely studied and found in manure, farm-amended soils, and air pollution from livestock farms. Therefore, MRS could also be found in them and they could be a source of these resistant bacteria for wild mammals (12).

Resistance to TE was $12 \%$ in our study. This antibiotic is widely used in veterinary practice (7) and shows a moderate bio-accumulation potential in plants (26), which probably explains its extensive distribution 
in wild animals representing a large range of habits, environments, and dispersal over all the geographical areas studied. Despite the wide use of sulphonamides in humans and animals (mainly the combined SXT), particularly in urinary infections and bovine mastitis $(11,16)$, no isolates resistant to SXT were recovered in the study. Some unknown factors could act in the wild mammals studied to block their acquisition of staphylococci resistant to this antibiotic. We detected a low prevalence of staphylococci resistant to CIP $(2.7 \%)$, in which three resistant isolates came from neonate or sub-yearling rabbits found in different geographical areas and different years, suggesting that these resistant isolates came from their family setting.

Isolates with ERY resistance were predominantly CoPS. This resistance has occasionally been associated with methicillin resistance in humans and farm animals (21), but only three isolates were also MRS in this study ( 2 S. aureus and $1 S$. sciuri). The targets of lincosamides (clindamycin and lincomycin) are bacterial ribosomes as they also are of macrolides (9), but the prevalences of resistance to ERY and LIN found in our study were different, and higher for LIN (32.4\%), isolates with resistance to which were detected in a high percentage in wild rabbit and common otter samples. Lincosamides are prescribed in human and animal medicine; high percentages of the antibiotic (around 75\%) could be excreted in faeces and urine, reaching water $(6,13)$, and human wastewater reaches rivers, also contributing to this environment pollution (1). Nevertheless, the omnivorous group carried a low proportion of staphylococci resistant to LIN, which could indicate this type of resistant bacteria and genetic elements are not widely disseminated.

We detected a low prevalence of MDR staphylococci isolates in the studied animals. The development of MDR is triggered by accumulation of resistance genes, vectored by plasmids or transposons that could be transferred between bacteria (19), and the antibiotic residues produced by humans and veterinary and agricultural activities. Antibiotic resistance is also produced without selective pressure, and this could explain the development of resistance in wildlife, in which the selective pressure is not so clear (2).

In conclusion, the majority of wild mammals included in this study came from geographical areas where agriculture and pig and sheep farms are widely distributed; however, the resistance values found in these wild mammals are lower than those to be expected if the use of antibiotics in farms had a direct influence on wildlife and its environment. On the other hand, resistance to antibiotics restricted to human use was widely disseminated in various wild animal species.

Conflict of Interests Statement: The authors declare that there is no conflict of interests regarding the publication of this article.
Financial Disclosure Statement: The authors declare that they did not have any funding source or grant to support their research work.

Animal Rights Statement: Collection of samples was conducted according to the guidelines of the Ethical Committee of Zaragoza University (Spain) (Rf: PI32/12).

Acknowledgements: The authors would like to thank the Council of the Community of Aragón, the Centre of Wild Fauna Recovery of La Alfranca (Aragón, Spain) and its main veterinarian Chabier Gonzalez-Estéban, and María Victoria Martínez Alfonso and Angel Luis Ortilles, veterinarians attending hunts.

\section{References}

1. Agga G.E., Arthur T.M., Durso L.M., Harhay D.M., Schmidt J.W.: Antimicrobial-Resistant Bacterial Populations and Antimicrobial Resistance Genes Obtained from Environments Impacted by Livestock and Municipal Waste. PLoS One 2015, 10: e0132586, doi: 10.1371/journal.pone.0132586.

2. Awad A., Arafat N., Elhadidy M.: Genetic elements associated with antimicrobial resistance among avian pathogenic Escherichia coli. Ann Clin Microbiol Antimicrob 2016, 15: 59, doi: 10.1186/s12941-016-0174-9.

3. Castanheira M., Watters A.A., Bell J.M., Turnidge J.D., Jones R.N.: Fusidic Acid Resistance Rates and Prevalence of Resistance Mechanisms among Staphylococcus spp. Isolated in North America and Australia, 2007-2008. Antimicrob Agents Chemother 2010, 54, 3614-3617, doi: 10.1128/AAC.01390-09.

4. Clinical and Laboratory Standards Institute: Performance Standards for Antimicrobial Susceptibility testing; Twenty-fifth Informational Supplement. CLSI document M100-S25. CLSI, Wayne, 2016.

5. Consejo Superior de Investigaciones Científicas: Enciclopedia virtual de los vertebrados españoles. Museo Nacional de Ciencias Naturales CSIC http://www.vertebradosibericos.org/mamiferos.html; Fauna Ibérica: Animales de España y Portugal. https://www. faunaiberica.org/.

6. Economou V., Gousia P.: Agriculture and food animals as a source of antimicrobial-resistant bacteria. Infect Drug Resist 2015, 8, 49-61, doi: 10.2147/IDR.S55778.

7. European Centre for Disease Prevention and Control, European Food Safety Authority, European Medicines Agency: Second joint report on the integrated analysis of the consumption of antimicrobial agents and occurrence of antimicrobial resistance in bacteria from humans and food-producing animals - Report. EFSA J 2017, 15, 4872, pp 135, doi:10.2903/j.efsa.2017.4872.

8. Food and Agriculture Organization, World Organisation for Animal Health, World Health Organisation: Sharing responsibilities and coordinating global activities to address health risks at the animal-human-ecosystems interfaces - A Tripartite Concept Note, 2010. http://www.who.int/influenza/resources/ documents/tripartite_concept_note_hanoi_042011_en.pdf.

9. Gold R.M., Lawhon S.D.: Incidence of Inducible Clindamycin Resistance in Staphylococcus pseudintermedius from Dogs. J Clin Microbiol 2013, 51, 4196-4199, doi: 10.1128/JCM.02251-13.

10. Holmes A.H., Moore L.S., Sundsfjord A., Steinbakk M., Regmi S., Karkey A., Guerin P.J., Piddock L.J.V: Understanding the mechanisms and drivers of antimicrobial resistance. Lancet 2016, 387, 176-187, doi: 10.1016/S0140-6736(15)00473-0.

11. Kemper N.: Veterinary Antibiotics in the Aquatic and Terrestrial Environment. Ecol Indc 2008, 8, 1-13, doi: 10.1016/j.ecolind. 2007.06.002 
12. Landers T.F., Cohen B., Wittum T.E., Larson E.L.: A Review of Antibiotic Use in Food Animals: Perspective, Policy, and Potential. Public Health Reports 2012, 127, 4-22, doi: 10.1177/003335491212700103.

13. Li L., Sun J., Liu B., Zhao D., Ma J., Deng H., Xue L., Fengyang H., Xiaoping L., Yahong L.: Quantification of lincomycin resistance genes associated with lincomycin residues in waters and soils adjacent to representative swine farms in China. Front Microbiol $2013,4,364$

14. Luzzago C., Locatelli C., Franco A., Scaccabarozzi L., Gualdi V., Vigano R., Sironi G., Besozzi M., Castiglioni B., Lanfranchi P., Cremonesi P., Battisti A.: Clonal diversity, virulence-associated genes and antimicrobial resistance profile of Staphylococcus aureus isolates from nasal cavities and soft tissue infections in wild ruminants in Italian Alpes. Vet Microbiol 2014, 170, 157-161, doi:10.3389/fmicb.2013.00364.

15. Magiorakos A.P., Srinivasan A., Carey R.B., Carmeli Y., Falagas M.E., Giske C.G., Harbarth S., Hindler J.F., Kahlmeter G., Olsson-Liljequist B., Paterson D.L., Rice L.B., Stelling J., Struelens M.J., Vatopoulos A., Weber J.T., Monnet D.L.: Multidrug-resistant, extensively drug-resistant and pandrug-resistant bacteria: an international expert proposal for interim standard definitions for acquired resistance. Clin Microbiol Infect 2012, 18, 268-281.

16. Marti E., Variatza E., Balcazar J.L.: The role of aquatic ecosystems as reservoirs of antibiotic resistance. Trends Microbiol 2014, 22, 36-41.

17. Molton J.S., Tambyah P.A., Ang B.S., Ling M.L., Fisher D.A.: The global spread of healthcare-associated multidrug-resistant bacteria: a perspective from Asia. Clin Infect Dis 2013, 56, 1310-1318, doi: 10.1093/cid/cit020.

18. Monecke S., Gavier-Widén D., Hotzel H., Peters M., Guenther S., Lazaris A. Loncaric I., Müller E., Reissig A., Ruppert-Lorz A., Shore A., Walter B., Coleman DC., Enrichit R.: Diversity of Staphylococcus aureus Isolates in European Wildlife. PLoS ONE 2016, 11, e0168433, doi: 10.1371/journal.pone.0168433.

19. Nikaido H.: Multidrug Resistance in Bacteria. Annu Rev Biochem $2009, \quad 78, \quad 119-146$, doi: 10.1146/annurev.biochem. 78.082907. 145923.

20. Poeta P., Costa D., Igrejas G., Rojo-Bezares B., Sáenz Y., Zarazaga M., Ruiz-Larrea F., Rodrigues J., Torres C.:
Characterization of vanA-containing Enterococcus faecium isolates carrying Tn5397-like and Tn916/Tn1545-like transposons in wild boars (Sus scrofa). Microb Drug Resist 2007, 13, 151-156, doi: 10.1089/mdr.2007.759.

21. Porrero M.C., Mentaberre G., Sánchez S., Fernández-Llario P., Casas-Díaz E., Mateos A., Vidal D., Lavin S., FernandezGaraizabal J.F., Dominguez L.: Carriage of Staphylococcus aureus by Free-Living Wild Animals in Spain. Appl Environ Microbiol 2014, 80, 4865-4870, doi: 10.1128/AEM.00647-14.

22. Ruiz-Ripa L., Alcalá L., Simón C., Gómez P., Mama O.M., Rezusta A., Zarazaga M., Torres C.: Diversity of Staphylococcus aureus clones in wild mammals in Aragon, Spain, with detection of MRSA ST130-mecC in wild rabbits. J Appl Microbiol. 2019, 127, 284-291, doi: 10.1111/jam.14301.

23. Schoenfelder S.M., Dong Y., Feßler A.T., Schwarz S., Schoen C., Köck R., Ziebuhr W.: Antibiotic resistance profiles of coagulasenegative staphylococci in livestock environments. Vet Microbiol 2017, 200, 79-87, doi: 10.1016/j.vetmic.2016.04.01

24. Seinige D.A., Von Altrock A., Kehrenberg C.: Genetic diversity and antibiotic susceptibility of Staphylococcus aureus isolates from wild boars. Comp Immunol Microbiol Infect Dis 2017, 54, 7-12, doi: 10.1016/j.cimid.2017.07.003.

25. Selva L., Viana D., Penadés J.R., Corpa J.M.: Staphylococcus aureus nasal carriage in rabbits. 9th World Rabbit Congress 2008, 10-13 June. Verona (Italia). World Rabbit Sci 2015, 23, 181-184, doi: $10.4995 /$ wrs. 2015.3960.

26. Tasho R.P., Cho J.Y.: Veterinary antibiotics in animal waste, its distribution in soil and uptake by plants: A review. Sci Total Environ 2016, 563-564, 366-376, doi: 10.1016/j.scitotenv. 2016.04.140.

27. Ventola C.L.: The Antibiotic Resistance Crisis: Part 1: Causes and Threats. PharmTher 2015, 40, 277-283.

28. World Organisation for Animal Health: The OIE Strategy on Antimicrobial Resistance and the Prudent Use of Antimicrobials. November 2016. http://www.oie.int/fileadmin/Home/eng/Media _Center/docs/pdf/PortailAMR/EN_OIE-AMRstrategy.pdf.

29. World Health Organization: Antimicrobial resistance: global report on surveillance, 2014. WHO Press, Geneva, 2014, pp. 256. 